\title{
Low adherence to national guidelines for thyroid screening in Down syndrome
}

\author{
Mark A. Fergeson, $M D^{I}$, John J. Mulvihill, $M D^{I}$, G. Bradley Schaefer, $M D^{2}$, Kristi A. DeHaai, BS $S^{3}$, \\ Jamie Piatt, $M P H^{I}$, Kathleen Combs, MD ${ }^{I}$, Brianna C. Bright, $M A^{1}$, and Barbara R. Neas, PhD ${ }^{4}$
}

\begin{abstract}
Purpose: To determine adherence to the American Academy of Pediatrics guidelines for thyroid screening in children with Down syndrome among primary care providers in the states of Oklahoma and Nebraska. Methods: We sought to identify all children with Down syndrome born in Oklahoma and Nebraska between 1994 and 2004 and review their medical records for evidence of thyroid screening. Patients were identified through a State Department of Health birth defects registry in Oklahoma and through participation in genetics clinics and laboratories in Nebraska and Oklahoma. Charts obtained from primary care providers were reviewed and the number of actual thyroid screens was compared with the number of recommended screens for each individual during the study period. Results: In Oklahoma, 13\% of participating children received all thyroid screens recommended in the guidelines. In Nebraska, $14 \%$ of children received all recommended thyroid screenings. Among participants in Oklahoma, a mean of $34 \%$ of recommended thyroid screenings were performed. In Nebraska, a mean of $45 \%$ of recommended thyroid screenings were performed. Conclusions: The level of adherence to the American Academy of Pediatrics guidelines for thyroid screening in children with Down syndrome is low. Factors contributing to this low level of adherence need to be identified and addressed. Genet Med 2009:11(7):548-551.
\end{abstract}

Key Words: Down syndrome, practice guidelines, guideline adherence, thyroid diseases, screening

$\mathrm{D}$ own syndrome is the most common chromosomal disorder in liveborn infants, occurring in approximately 1 in 600 births, and is associated with several complex medical conditions. For these reasons, physicians and others who provide medical care for children are likely to encounter patients with Down syndrome on a routine basis. The association between Down syndrome and thyroid dysfunction is well established..$^{1-5}$ Although the reported frequency of hypothyroidism in patients with Down syndrome varies with study design and the ages of patients studied, both longitudinal and cross-sectional studies have demonstrated a significantly increased frequency of hypothyroidism among children and adults with Down syndrome. ${ }^{1-6}$ By adulthood, the reported cumulative incidence may approach

\footnotetext{
From the ${ }^{1}$ Department of Pediatrics, University of Oklahoma Health Sciences Center, Oklahoma City, Oklahoma; ${ }^{2}$ Division of Medical Genetics, University of Arkansas for Medical Sciences, Little Rock, Arkansas: ${ }^{3} \mathrm{Mu}-$ nroe-Meyer Institute for Genetics and Rehabilitation, University of Nebraska Medical Center, Omaha, Nebraska; and ${ }^{4}$ Department of Biostatistics and Epidemiology, University of Oklahoma Health Sciences Center, Oklahoma City, Oklahoma.

Mark Fergeson, MD, University of Oklahoma Health Sciences Center, 940 NE 13th Street, Room 1B-1306, Oklahoma City, OK 73104. E-mail: markfergeson@ouhsc.edu.
}

Disclosure: The authors declare no conflict of interest

Submitted for publication November 21, 2008

Accepted for publication March 24, 2009

DOI: $10.1097 /$ GIM.0b013e3181a9c250
$30 \% .^{2}$ Studies of thyroid function in adults with Down syndrome have revealed that $8-10 \%$ of patients had previously unrecognized hypothyroidism requiring medical intervention. , $^{7}$ Furthermore, because many of the symptoms of hypothyroidism in children are also features of Down syndrome (delayed development, increased body mass index, decreased linear growth, constipation, and muscle weakness), impaired thyroid function may be difficult to detect clinically in this group of patients. The frequency of hyperthyroidism is less well established, but it seems higher in children with Down syndrome than in those without it. ${ }^{2}$

To guide care, the American Academy of Pediatrics (AAP) Committee on Genetics issued a policy statement entitled, "Health Supervision for Children with Down syndrome," in 1994 and revised their recommendations in 2001.8,9 Both guidelines recommended screening of children with Down syndrome for thyroid disease at ages 6 months, 12 months, and annually thereafter.

In the United Kingdom, a similar guideline has been published and recommends biochemical screening for thyroid dysfunction at least every 2 years after the first year of life. ${ }^{10}$ Among pediatricians in the United Kingdom, $71 \%$ of those who responded to a survey reported adhering to the national recommendations for thyroid screening in patients with Down syndrome. ${ }^{11}$ However, recent studies evaluating adherence to AAP practice guidelines for other pediatric conditions have revealed poor adherence among clinicians in the United States. ${ }^{12,13} \mathrm{We}$ reviewed the medical records of children born with Down syndrome in Oklahoma and Nebraska to determine adherence to the AAP guidelines on thyroid screening.

\section{MATERIALS AND METHODS}

We sought to identify all children with Down syndrome born in Nebraska and Oklahoma between January 1994 and December 2004 and to review their medical records for documentation of thyroid screening. Documentation of an order for a thyrotropin level (thyroid stimulating hormone [TSH]), a thyroxine level (T4), or a free thyroxine level (fT4), or the results of a measured level of one of those biochemical markers was considered evidence of thyroid screening. We chose to identify children born after 1994, the year in which the AAP policy statement was first published. We also chose to evaluate children who were at least 6 months of age when data collection began because this is the age at which first thyroid screening is recommended beyond the neonatal period.

In Nebraska, patients were identified through their participation in the clinical genetics services (clinics and laboratory) at the Munroe-Meyer Institute for Genetics and Rehabilitation. In Oklahoma, patients were identified through the Oklahoma Birth Defects Registry of the State Department of Health or through their participation in the Genetics clinic or laboratory at the University of Oklahoma Health Sciences Center. Letters offering participation in the study were sent to the parents of children 
identified as having Down syndrome. Two follow-up letters were sent to maximize enrollment. Once enrolled, parents were asked to permit release of all medical records from each primary care physician who provided care for the enrolled child between 1994 and 2007. The study was approved by the Institutional Review Boards of the Munroe-Meyer Institute for Genetics and Rehabilitation, the University of Oklahoma Health Sciences Center, and the Oklahoma State Department of Health. Informed consent was obtained from the parents of all participating patients.

For many subjects, medical records covering the child's complete life span were not available. In these cases, we accepted data only if an entire year's worth of medical records were available, because the AAP guidelines recommend annual screening. Screening tests to be performed at 6 months of age were allowed a window of \pm 1 month and annual thyroid tests were allowed a window of \pm 3 months to be deemed, "in adherence." For children eventually diagnosed with thyroid disease, we determined adherence with the screening recommendations up to the time of diagnosis with thyroid disease. Patients identified with thyroid disease at birth were excluded from the study.

\section{RESULTS}

In Nebraska, a total of 299 patients were identified and 107 responses to the mailings were received. Two declined to participate. Of the 105 subjects whose caregivers agreed to participate, records were obtained for 80 subjects. The records of these 80 subjects, representing $27 \%$ of identified children, were reviewed for evidence of thyroid screening. Of these 80 subjects, $11(14 \%)$ were $100 \%$ adherent to the guidelines. On the basis of the duration of follow-up, a mean of five screening thyroid tests were recommended per child during the study period and, according to medical records, a mean of 2.1 thyroid screening tests per child were actually performed. This resulted in a mean compliance rate of $45 \%$ among the Nebraska cohort (Table 1).

In Oklahoma, 565 patients were identified and 96 families responded the mailings. Three declined to participate. Of the 93 subjects whose caregivers agreed to participate, investigators were able to obtain the medical records of 48 subjects. The records of these 48 subjects, representing $8 \%$ of identified children, were reviewed for evidence of thyroid screening. Of the 48 subjects in Oklahoma, $6(13 \%)$ were $100 \%$ adherent to the guidelines. A mean of 3.4 screening thyroid tests per child were recommended during the study period and a mean of 1.1 thyroid screening tests per child were actually performed, re-

Table 1 Adherence to recommendations for thyroid screening by state, Nebraska and Oklahoma

\begin{tabular}{|c|c|c|}
\hline State & $\begin{array}{l}\text { Nebraska } \\
(N=80)\end{array}$ & $\begin{array}{l}\text { Oklahoma } \\
(N=48)\end{array}$ \\
\hline No. $100 \%$ adherent patients $(\%)$ & $11(14)$ & $6(13)$ \\
\hline Mean No. screenings recommended per child & 5.0 & 3.4 \\
\hline Mean No. screenings performed per child & 2.1 & 1.1 \\
\hline Mean compliance rate per child ${ }^{a}(\%)$ & 45 & 34 \\
\hline
\end{tabular}

sulting in a mean compliance rate of $34 \%$ among the Oklahoma cohort (Table 1).

Patients in each state were identified through different methods and therefore the data were not combined. There was no statistically significant association between state and $100 \%$ adherence to the guidelines ( $\chi^{2}$ analysis, $P=0.84$ ). However, the overall compliance rate was significantly higher among Nebraska patients compared with Oklahoma patients (Wilcoxon test, $P=0.05$ ). We also sought to determine if there was an association between attendance at a genetics clinic at the participating academic centers and adherence to the guidelines. In Nebraska, 12 of 80 subjects $(15 \%)$ had attended the genetics clinic at the Munroe-Meyer Institute and in Oklahoma 13 of 48 subjects $(27 \%)$ had attended the genetics clinic at the University of Oklahoma Health Sciences Center. We found that there was no statistically significant association between state and genetics clinic attendance ( $\chi^{2}$ analysis, $P=0.10$ ), between genetic clinic attendance and median compliance rate (Wilcoxon test, $P=0.54)$ or genetics clinic attendance and $100 \%$ adherence $\left(\chi^{2}\right.$ analysis, $P=0.33$ ).

In addition, we sought to determine if the age of the subjects during the study period was associated with compliance rate. We found that age (in years) was not significantly correlated with mean compliance rate in either state (Nebraska, $P=0.20$; Oklahoma, $P=0.69$ ). However, in Nebraska there was a significant difference in the median age of those subjects who were $100 \%$ adherent to the guidelines compared with those who were not $(P=0.001)$. In Oklahoma, there was also a difference in the median age of those subjects who were $100 \%$ adherent compared with those who were not; however, this difference did not reach statistical significance (Table 2).

\section{DISCUSSION}

Thyroid disease, particularly hypothyroidism, is common among children with Down syndrome. Hypothyroidism may be more difficult to diagnose in children with Down syndrome because of the overlap of the early clinical signs of hypothyroidism and the common features of Down syndrome. For this reason, the AAP has recommended early and frequent screening for thyroid disease in these children. Our findings indicate a low level of adherence to these recommendations among primary care providers. The total number of patients in the study who were evaluated at genetics clinics in the respective states was small and evaluation in the subspecialty genetics clinic did not seem to significantly improve the adherence rate. In both states, the median age of patients who were $100 \%$ adherent to the guidelines was younger than patients who were not $100 \%$ adherent and this was statistically significant among the patients in Nebraska. The lack of statistical significance in the age

Table 2 Adherence to recommendations by age, Nebraska and Oklahoma

\begin{tabular}{lcc}
\hline State & $\begin{array}{c}\text { Nebraska } \\
(N=80)\end{array}$ & $\begin{array}{c}\text { Oklahoma } \\
(N=48)\end{array}$ \\
\hline $\begin{array}{l}\text { Age ranges of patients in years } \\
\text { (median) }\end{array}$ & $0.5-10(4)$ & $1-10(2)$ \\
$\begin{array}{l}\text { Median age of patients who were 100\% } \\
\text { adherent (yr) }\end{array}$ & 1 & 1.5 \\
$\begin{array}{l}\text { Median age of patients not 100\% } \\
\text { complaint (yr) }\end{array}$ & 4 & 2.5 \\
\hline
\end{tabular}


difference among the Oklahoma patients may be related to the smaller sample size. One potential explanation for the better adherence among younger patients may be that encounters with primary care physicians are more frequent for children at younger ages and parents and clinicians may be more vigilant when children are younger.

Some authors, however, have called into question the advisability of annual thyroid screening in children with Down syndrome. ${ }^{5,14}$ Among patients with Down syndrome, there is a high incidence of isolated increased TSH with normal fT4 levels in the absence of clinical signs of hypothyroidism. This condition has alternatively been termed subclinical hypothyroidism, implying a biochemical variation with no overt clinical consequences. ${ }^{1,5,14-18}$ The concern is that the identification of such children through frequent laboratory screening is unnecessary and may result in over diagnosis and treatment.

The significance and natural history of isolated elevated TSH with normal fT4 in patients with Down syndrome remains unclear. Some of these patients clearly go on to develop overt hypothyroidism on repeat testing. ${ }^{14,19}$ However, some children with Down syndrome demonstrate a persistently elevated TSH for at least several years without developing overt hypothyroidism, whereas others revert to normal. ${ }^{3,14,19}$ This information highlights the need for careful interpretation of the biochemical results of thyroid screening among children with Down syndrome. However, in some studies persons with Down syndrome with isolated elevated TSH values have been shown to have lower intelligence quotient (IQ) scores and lower adaptive behavior than euthyroid patients with Down syndrome. ${ }^{18,20,21}$ In addition, neonates with Down syndrome who were treated with thyroxine despite normal newborn screening results had less motor delay and better growth at 2 years of age than children with Down syndrome who received placebo. ${ }^{22}$ More research is needed to elucidate the relationship between elevated TSH and possible morbidity and response to treatment in this population.

There is no question that the risk of acquiring thyroid disease persists throughout childhood and into adulthood for these patients. Down syndrome is a relatively common condition that most physicians caring for children will encounter in clinical practice. For these and other reasons, expert panels in both the United States and the United Kingdom have determined that early and frequent laboratory screening is needed to identify children at risk for developing morbidity related to undiagnosed thyroid disease. Although $71 \%$ of physicians in the United Kingdom reported adhering to the national recommendations for thyroid screening on a survey, actual rates of documented screenings may, in fact, be lower than that reported. In light of the results of previous studies in older children and adults with Down syndrome, the low level of adherence found in the current study is likely to lead to under diagnosis of hypothyroidism in this population. Indeed, studies in adult patients with Down syndrome have revealed a high incidence of undiagnosed hypothyroidism. ${ }^{7,15}$

The current study is limited by the marginal response rate among recruited patients identified with Down syndrome in the respective states, especially in Oklahoma. In Oklahoma, patients were identified through the Oklahoma Birth Defects Registry and therefore current addresses were not available for many registered subjects. Another limitation is the fact that medical records for each patient's entire life span were often not available and determination of adherence could only be ascertained for the time periods in which medical records were available. In addition, it is possible that some thyroid screening tests were performed on the study patients but not documented in primary care physician's medical records. However, subspe- cialist's records were evaluated when available and ensuring compliance with routine screening measures is clearly within purview of primary care physicians. Other factors that may affect compliance with the screening guidelines but were not evaluated in the current study include patient socioeconomic status, comorbid medical conditions, or the location and type of primary care provider (nurse practitioner, pediatrician, or family physician).

The low level of adherence to screening recommendations in this study is concerning and suggests a need to identify factors contributing to poor adherence to the AAP policy statement and other practice guidelines. Several published studies have sought to identify barriers to guideline implementation and identify strategies for improvement. Broad dissemination of guidelines, frequent clinical reminders, and auditing activities for quality assurance seem to all be important in improving adherence to clinical guidelines. ${ }^{23,24}$ Additionally, it is important to provide information regarding screening recommendations to the families of affected children. Other potential factors contributing to the low adherence may include parental and patient resistance to obtaining blood tests and the lack of a medical home among patients with Down syndrome. Research to determine adherence to the other recommendations contained within the AAP Policy Statement, "Health Supervision for Children with Down syndrome," would also be helpful.

\section{ACKNOWLEDGMENTS}

Support for this work was provided by a Grant from HRSA/ Maternal and Child Health Bureau (Genetic Services Branch) U22MC03962, Heritable Disorders Heartland Collaborative, through the University of Oklahoma Health Sciences Center.

We thank Kay Pearson at the Oklahoma State Department of Health for her assistance and support of this project. We also thank Paul Marmen, Sana Rettig, Jennifer Unruh, and the Pediatric Research Programs at the University of Oklahoma for their assistance and support. We thank the parents of children with Down syndrome in Oklahoma and Nebraska and to the primary care providers, who provide them with medical care.

\section{REFERENCES}

1. Gruneiro de Papendieck L, Chiesa A, Bastida MG, Alonso G, Finkielstain G, Heinrich JJ. Thyroid dysfunction and high thyroid stimulating hormone levels in children with Down's syndrome. J Pediatr Endocrinol Metab 2002; $15: 1543-1548$

2. Karlsson B, Gustafsson J, Hedov G, Ivarsson SA, Anneren G. Thyroid dysfunction in Down syndrome: relation to age and thyroid autoimmunity. Arch Dis Child 1998;79:242-245.

3. Rooney S, Walsh E. Prevalence of abnormal thyroid function tests in a Down syndrome population. Ir J Med Sci 1997;166:80-82.

4. Pueschel SM, Pezzullo JC. Thyroid dysfunction in Down syndrome. Am J Dis Child 1985;139:636-639.

5. Prasher V, Haque MS. Misdiagnosis of thyroid disorders in Down syndrome: time to reexamine the myth? Am J Ment Retard 2005;110:23-27.

6. Pueschell SM, Jackson IM, Giesswein P, Dean MK, Pezzullo JC. Thyroid function in Down syndrome. Res Dev Disabil 1991;12:287-296.

7. Friedman DL, Kastner T, Pond WS, O'Brien DR. Thyroid dysfunction in individuals with Down syndrome. Arch Intern Med 1989;149:1990-1993.

8. American Academy of Pediatrics Committee on Genetics. Health supervision for children with Down syndrome. Pediatrics 1994;93:855-859.

9. American Academy of Pediatrics Committee on Genetics. Health supervision for children with Down syndrome. Pediatrics 2001;107:442-449.

10. The Down Syndrome Medical Interest Group. Guidelines for Essential Medical Surveillance. Available at: http://dsmig.org.uk/publications/guidelines. Accessed August 28, 2007

11. Varadkar S, Bineham G, Lessing D. Thyroid screening in Down's syndrome: current patterns in the UK. Arch Dis Child 2003;88:645-649.

12. Cohen AL, Rivera FP, Davis R, Christakis DA. Compliance with guidelines for the medical care of first urinary tract infections in infants: a population based study. Pediatrics 2005;115:1474-1478. 
13. Sand N, Silverstein M, Glascoe FP, Gupta VB, Tonniges TP, O'Conner KG Pediatricians' reported practices regarding developmental screening: do guidelines work? Do they help? Pediatrics 2005;116:174-179.

14. Gibson PA, Newton RW, Selby K, Price DA, Leyland K, Addison GM. Longitudinal study of thyroid function in Down syndrome in the first two decades. Arch Dis Child 2005;90:574-578.

15. Prasher V, Gomez G. Natural history of thyroid function in adults with Down syndrome-10 year follow-up study. J Intellect Disabil Res 2007;51:312-317.

16. Noble SE, Leyland K, Findlay CA, et al. School based screening for hypothyroidism in Down's syndrome by dried blood spot TSH measurement. Arch Dis Child 2000;82:27-31.

17. Van Trotsenburg AS, Kempers MJ, Endert E, Tijssen JG, deVijlder JJ, Vulsma T. Trisomy 21 causes persistent congenital hypothyroidism presumably of thyroidal origin. Thyroid 2006;16:671-680.

18. Tuysuz B, Beker DB. Thyroid dysfunction in children with Down's syndrome. Acta Paediatr 2001;90:1389-1393.

19. Selikowitz M. A five-year longitudinal study of thyroid function in children with Down syndrome. Dev Med Child Neurol 1993;35:396401

20. Mancini A, Mariotti P, Conte G, et al. Hormonal and metabolic evaluation in Down's syndrome: preliminary evidence for TSH dysregulation in hyperthyrotropinemic patients. Exp Clin Endocrinol Diabetes 2006;114:39-40.

21. Bhaumik S, Collacott RA, Garrick P, Mitchell C. Effect of thyroid stimulating hormone on adaptive behavior in Down's syndrome. J Ment Defic Res 1991;35(Pt 6):512-520.

22. Van Trotsenburg AS, Vulsma T, van Rozenburg-Marres SL, et al. The effect of thyroxine treatment started in the neonatal period on development and growth of two-year-old Down syndrome children: a randomized clinical trial. J Clin Endocrinol Metab 2005;90:3304-3311.

23. Cabana MD, Rand CS, Powe NR, et al. Why don't physicians follow clinical practice guidelines? A framework for improvement. JAMA 1999; $82: 1458-1645$.

24. Livesay EA, Noon JM. Implementing guidelines: what works. Arch Dis Child Educ Pract Ed 2007;92:129-134. 